Michael H. Stoffel • Armin E. Friess

\title{
Demonstration and cytochemical analysis of anionic sites on ejaculated boar spermatozoa: a scanning electron microscopy study using cationised colloidal gold
}

Accepted: 26 October 2001 / Published online: 23 November 2001

(C) Springer-Verlag 2001

\begin{abstract}
The plasmalemma of spermatozoa bears negative charges as is the case for most mammalian cells. This has been concluded from the sperm cell's electrophoretic behaviour and from labelling experiments with various cationic probes followed by transmission electron microscopy of ultrathin sections. An overall view of the cell surface, however, is necessary in order to assess the distribution and density of the anionic sites adequately. We, therefore, used scanning electron microscopy in combination with cationised colloidal gold labelling to analyse the presence of anionic sites on ejaculated boar spermatozoa. Incubations were performed at $\mathrm{pH} 3.5,2.5$ and 1.0. Labelling was specific and bound gold particles were unequivocally identified using the backscattered electron signal. The chemical nature of the anionic sites involved was investigated by treating spermatozoa with pronase, phosphatase and neuraminidase as well as by methylation, acid hydrolysis and $\beta$-elimination prior to cationised gold labelling. Our results suggest that besides phosphates, carboxyl groups are predominantly accountable for the binding of cationised colloidal gold. Presumptive macromolecules bearing these anionic sites are phospholipids and sialic acid residues. The combination of methods presented herewith should be of value in order to elucidate charge interactions which have been shown to play a role in cellular recognition events and adhesion.
\end{abstract}

Keywords Negative charges - Sialic acid - Carboxyl groups $\cdot$ Cell-cell interactions

M.H. Stoffel ( $)$ A.E. Friess

Department of Veterinary Anatomy,

University of Berne Veterinary School,

Länggass-Strasse 120, 3012 Bern, Switzerland

e-mail: michael.stoffel@ita.unibe.ch

Tel.: +41-31-6312205, Fax: +41-31-6312615

\section{Introduction}

Like most mammalian cells, spermatozoa bear a net negative surface charge. This has long been known since sperm cells exposed to an electric field migrate toward the anode (Bedford 1963; Nevo et al. 1961). Further evidence came from observations on isoelectric focusing of sperm cells (Moore 1979) and from direct detection of anionic sites in transmission electron microscopy by means of cationic probes such as colloidal iron hydroxide, ruthenium red and cationised ferritin (Danon et al. 1972; Delgado et al. 1990; Fléchon 1975; Lopez et al. 1987; Yanagimachi et al. 1972). Recently, the interest in the presence and distribution of electrical charges at the cell surface has met a revival since electrostatic phenomena are likely to play a pivotal role in cell-cell interactions in general and fertilisation in particular (Iqbal and Hunter 1995; Philip et al. 1997). To date, however, ultrastructural localisation of anionic sites at the sperm surface only has been achieved by transmission electron microscopy and information on density and distribution of negative charges has been drawn from cross-sectional views. Although these techniques allowed anionic sites to be localised to the glycocalyx, the use of ultrathin sections inevitably imposed tangible limitations on the assessment of labelling density at the cell surface. Provided suitable probes are available, scanning electron microscopy (SEM) unquestionably would be a more adequate approach to provide an overall picture of the sperm surface and to address this issue. Colloidal gold has been introduced in recent years as a cationic probe (Kashio et al. 1992; Ohtsuka and Murakami 1994; Saga 1998; Skutelsky and Roth 1986; Skutelsky et al. 1995). This lead us to attempt to track the anionic charges by means of cationised gold and using the backscattered electron signal in SEM. The goals of the present study, therefore, were to demonstrate the presence and distribution of negative charges on sperm cells by SEM and to provide information on their chemical nature by selective removal. 


\section{Materials and methods}

Materials

Spermatozoa were obtained from a boar station providing boar semen for artificial insemination (SUISAG, Knutwil, Switzerland). Ejaculates were collected with an artificial vagina and suspended in an appropriate extender (modified after Pursel and Johnson 1976) for transport. Experiments were performed at least in triplicate and a minimum of 50 sperm cells per sample were examined by SEM.

Methods

Washing and fixation of sperm cells

Upon receipt, $1 \mathrm{ml}$ sperm suspension was added to $12 \mathrm{ml}$ washing solution $(6 \% \mathrm{w} / \mathrm{v}$ D-glucose, $0.37 \% \mathrm{w} / \mathrm{v}$ trisodium dihydrate, $0.37 \% \mathrm{w} / \mathrm{v}$ disodium EDTA, $0.12 \% \mathrm{w} / \mathrm{v}$ sodium hydrogen carbonate, $\mathrm{pH}$ 7.2) and centrifuged at $180 \mathrm{~g}$ for $15 \mathrm{~min}$. Sperm cells were washed two more times with intervening centrifugation. The final sperm pellet was resuspended in $1 \mathrm{ml}$ PBS. Where appropriate, sperm cells were fixed in $1 \%$ paraformaldehyde, $1 \%$ glutaraldehyde in $0.2 \mathrm{M}$ cacodylate buffer $(\mathrm{pH} 7.4)$ for $1 \mathrm{~h}$ at room temperature. Free aldehydes were blocked thereafter with $0.2 \mathrm{M}$ glycine in $0.1 \mathrm{M}$ PBS ( $\mathrm{pH} 7.2$ ) at $4^{\circ} \mathrm{C}$ overnight in order to block the negative charges of free aldehyde residues (Torihara et al. 1995).

\section{Enzymatic treatment}

Washed but unfixed sperm cells were incubated for $3 \mathrm{~h}$ at room temperature in the presence of the respective enzyme. Enzymatic treatments with pronase, phosphatase (acid phosphatase from sweet potato) and neuraminidase (type $\mathrm{V}$ from $\mathrm{Cl}$. perfringens) were performed at $\mathrm{pH} 5.3$, but at $\mathrm{pH} 4.5$ for $\alpha$-mannosidase (Parillo et al. 1997; Wall et al. 1995). The final concentration of all enzymes was $1 \mathrm{IU} / \mathrm{ml}$ in washing solution. After enzymatic digestion, sperm cells were fixed as described above. All enzymes were purchased from Sigma (Buchs, Switzerland).

\section{Methylation}

Sperm cells were washed and fixed as described above. After blocking free aldehydes with $0.2 \mathrm{M}$ glycine in PBS, samples were incubated in $0.1 \mathrm{~N} \mathrm{HCl}$ in methanol for $24 \mathrm{~h}$ at $60^{\circ} \mathrm{C}$ (Friess and Liebich 1972; Gasic et al. 1968; Lillie 1965).

\section{$\beta$-elimination}

Fixed sperm cells were resuspended in $0.5 \mathrm{~N} \mathrm{NaOH} / 70 \%$ ethanol and incubated for 7 days at $4^{\circ} \mathrm{C}$. Samples were then washed with $70 \%$ ethanol (Leis et al. 1997; Ono et al. 1983).

\section{Acid hydrolysis}

Samples were fixed as described above. Pellets were then incubated in $0.1 \mathrm{M} \mathrm{HCl}$ for $2-3 \mathrm{~h}$ at $82^{\circ} \mathrm{C}$ (Leis et al. 1997).

\section{Labelling with colloidal gold at $\mathrm{pH} 2.5$}

Prior to proceeding with the gold labelling, all samples were resuspended in $0.05 \mathrm{M}$ TRIS ( $\mathrm{pH} 2.5$ ). Aliquots of treated and untreated samples were then incubated with 15-nm cationic gold (British BioCell International, Basel, Switzerland) at a dilution of 1:50 in $0.05 \mathrm{M}$ TRIS ( $\mathrm{pH} 2.5$ ) for $2 \mathrm{~h}$ at room temperature and overnight at $4^{\circ} \mathrm{C}$ (Skutelsky and Roth 1986; Skutelsky et al.
1995). After two more washing steps, sperm cells were adsorbed onto gold-sputtered coverslips which had been precoated with poly-L-lysine.

\section{Labelling with colloidal gold at $\mathrm{pH} 1$}

Fixed but otherwise untreated sperm cells were suspended in potassium chloride- $\mathrm{HCl}$ buffer ( $\mathrm{pH}$ 1) and incubated with colloidal gold as described above (Ueda et al. 1998).

\section{Controls}

In all experiments, control samples were preincubated with $1 \mathrm{mg} / \mathrm{ml}$ poly-L-lysine in $0.05 \mathrm{M}$ TRIS ( $\mathrm{pH} 2.5$ ) for $1 \mathrm{~h}$ at room temperature prior to cationic gold labelling. Furthermore, when sperm samples were subjected to chemical or enzymatic procedures prior to the gold labelling, sham-treated control aliquots were incubated with washing solution instead of the corresponding treatment. Again, these samples were split into two aliquots, one of which was incubated with poly-L-lysine prior to the colloidal gold labelling.

\section{Processing for SEM}

Samples were osmicated in $1.33 \% \mathrm{OsO}_{4}$ with $0.11 \%$ ruthenium red in 0.13 M cacodylate buffer ( $\mathrm{pH} 7.4$; Stoffel et al. 1991), dehydrated through an ascending alcohol series and critical-point dried in a CPD 030 (Bal-Tec, Balzers, Liechtenstein) or dried by evaporation of hexamethyldisilazane (Sigma, Buchs, Switzerland; Braet et al. 1997; Ting-Beall et al. 1995). Secondary electron and corresponding backscattered electron images were obtained with a scanning electron microscope DSM 982 Gemini (Leo, Oberkochen, Germany) at an accelerating voltage of $5 \mathrm{kV}$.

\section{Results}

\section{Untreated sperm cells}

Labelling of untreated sperm cells at pH 3.5 (not shown) and at $\mathrm{pH} 2.5$ (Fig. 1a, b, d, e, h, i) yielded identical results. Distribution of anionic sites on sperm heads was uniform and of considerable density. Gold particles were spread evenly over the anterior acrosomal, the equatorial and the postacrosomal segments of the sperm head plasma membrane (Fig. 1a-c). Labelling density on sperm tails was comparable to or lower than that observed on sperm heads (Fig. 1d, e). After incubating the sperm cells with colloidal gold at $\mathrm{pH} 1$, no labelling was present (Fig. 1f, g). Preincubation of control samples with poly-L-lysine effectively prevented labelling with cationised colloidal gold (Fig. 1h, i).

\section{Treated sperm cells}

The labelling pattern of anionic sites on sperm cells was altered by foregoing treatment with neuraminidase. A difference in cationised gold binding was noted between acrosomal and postacrosomal regions. Whereas the density in the postacrosomal region was not diminished as compared to untreated cells, the number of anionic sites 

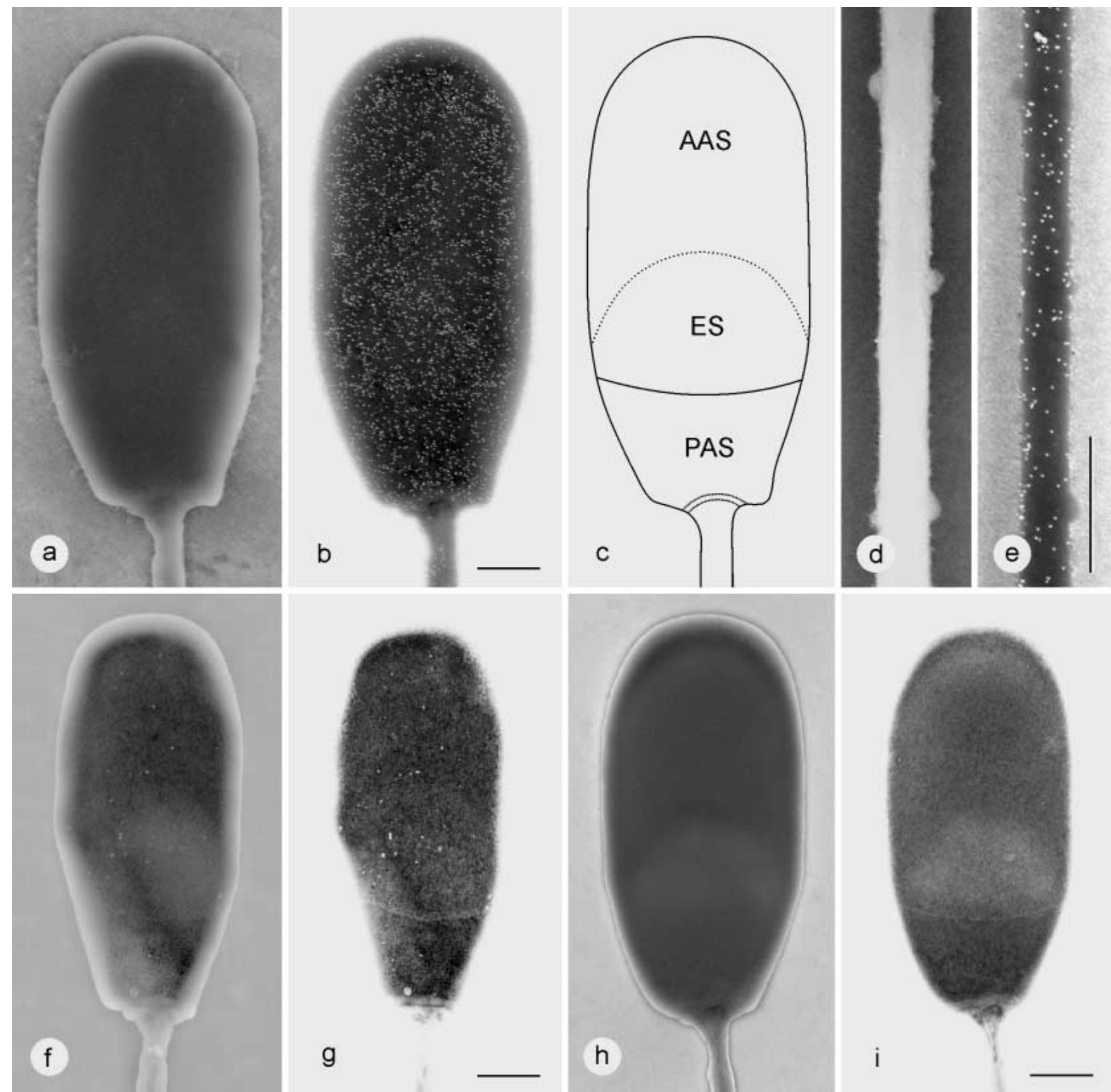

Fig. 1a-i Labelling of untreated spermatozoa with 15-nm cationised colloidal gold. At $\mathrm{pH} 2.5(\mathbf{a}, \mathbf{b}, \mathbf{d}, \mathbf{e}, \mathbf{h}, \mathbf{i})$ anionic sites were evenly distributed over the anterior acrosomal (c; $A A S)$, the equatorial $(\mathbf{c} ; E S)$ and the postacrosomal segments $(\mathbf{c} ; P A S)$ of the sperm head plasma membrane $(\mathbf{a}, \mathbf{b})$. Labelling density on sperm tails (d, e) was inferior to head labelling. No labelling was detected at $\mathrm{pH} 1$ (f, $\mathbf{g})$. Preincubation of sperm cells with poly-L-lysine completely prevented binding of cationised gold particles $(\mathbf{h}, \mathbf{i})$. Secondary electron micrographs showing plasmalemma $(\mathbf{a}, \mathbf{d}, \mathbf{f}, \mathbf{h})$ and backscattered electron micrographs revealing bound gold particles $(\mathbf{b}, \mathbf{e}, \mathbf{g}, \mathbf{i})$. Bar $1 \mu \mathrm{m}$

on the acrosomal plasma membrane was reduced (Fig. 2a, b). The opposite effect was observed after phosphatase digestion since labelling was virtually absent from the postacrosomal region while still being present over both the acrosomal and the equatorial segments (Fig. 2c, d). Pronase did affect plasma membrane integrity in most cells thus making assessment of labelling density difficult (not shown). As compared to sham-treated sperm cells (not shown), exposure to mannosidase barely reduced the number of anionic sites as evidenced by colloidal gold labelling (Fig. 2e, f).

Acid hydrolysis (Fig. 2g, h), methylation (Fig. 2i, j) and $\beta$-elimination (Fig. 2k, 1), however, completely abolished binding of cationised colloidal gold to sperm cells. 

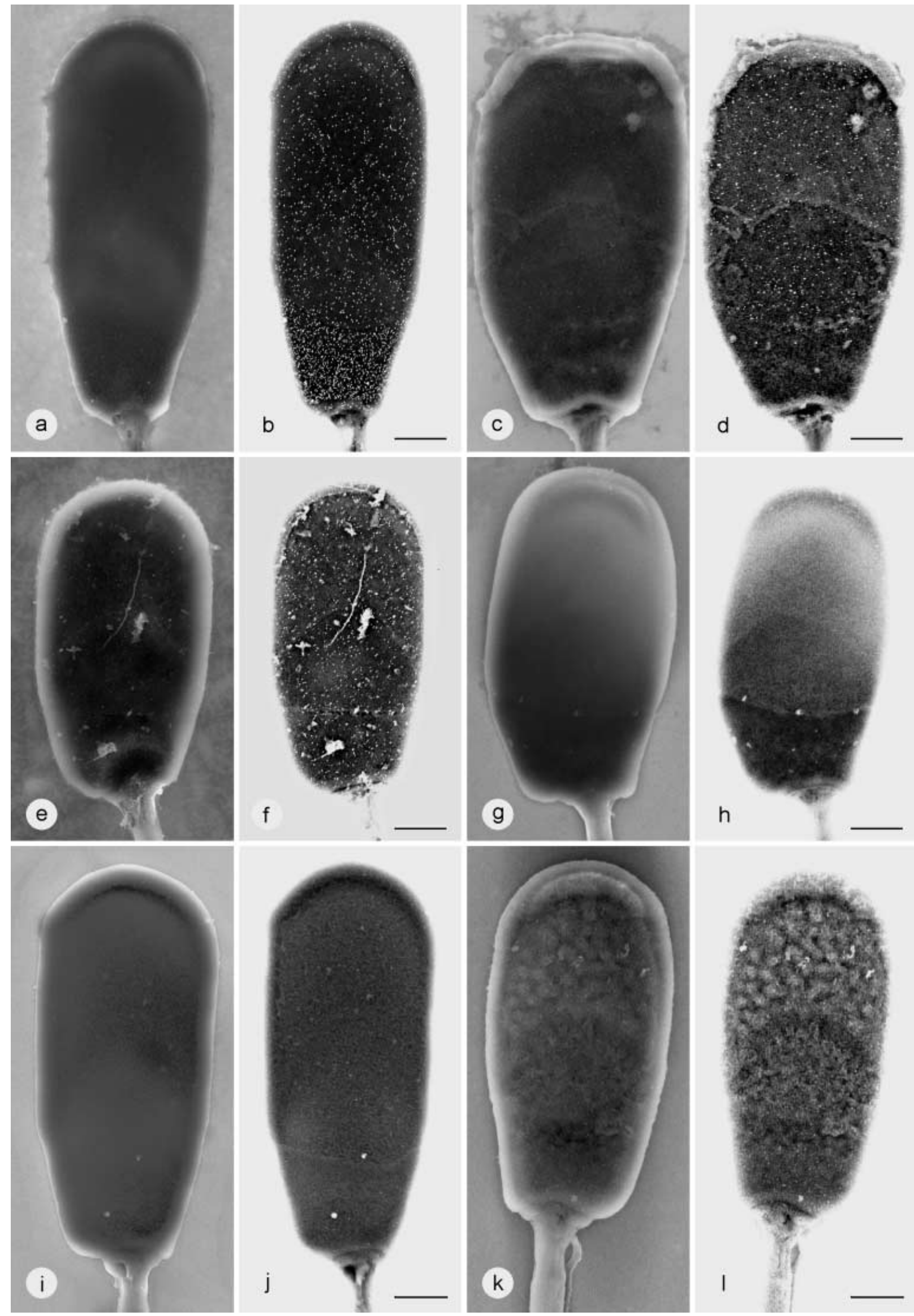


\section{Discussion}

In the present study, we successfully used cationised colloidal gold and SEM to demonstrate anionic sites on ejaculated boar spermatozoa. Bound gold particles were detected by collecting the backscattered electron signal and, thus, we were able to clearly visualise the presence and distribution of discrete negative charges at the surface of boar ejaculated spermatozoa. In addition, we used enzymatic and cytochemical treatments in order to narrow down the wide range of possible acidic groups.

In our experiments, labelling at $\mathrm{pH} 2.5$ was uniform in all three plasma membrane domains of the sperm heads. Labelling density was never found to be higher on sperm tails than on sperm heads. This is in agreement with previous reports in this species since fewer negative charges on tails than on heads have been demonstrated on boar (Delgado et al. 1990), stallion (Lopez et al. 1987), bull and human sperm cells (Yanagimachi et al. 1972). However, there seem to be substantial interspecies differences. In ejaculated or cauda epididymal spermatozoa from rabbit, mongoose, rat, guinea-pig and hamster, heavier iron hydroxide labelling of sperm tails as compared to the sperm heads has been reported (Fléchon 1975; Yanagimachi et al. 1972). Rabbit sperm cells also point their tails towards the anode when exposed to an electrostatic field (Bedford 1963). Electrophoretic behaviour, however, does not say anything about the absolute number of negative charges present but only about the net electrical charge. In order to monitor the actual density and distribution of binding sites, SEM is likely to yield the most reliable information and the comparative aspect of interspecies differences should, thus, be revisited.

The binding of cationised colloidal gold particles to negative charges rests on an electrostatic interaction. Ionisation at low $\mathrm{pH}$ can be ascribed to acidic groups such as carboxyl groups of glycoproteins and/or glycolipids associated with sialic acid residues, sulphated polysaccharides and phosphate groups of phospholipids. From these, only sulphates are still being ionised at $\mathrm{pH} 1$ (Kashio et al. 1992). Since no labelling of the sperm surface was detected at $\mathrm{pH} 1$, sulphates do not seem to contribute significantly to making the boar sperm surface electronegative. This conclusion is in conflict with a report associating the binding of ruthenium red to the presence of heparin sulphate at the sperm surface (Delgado

4 Fig. 2a-l Labelling of spermatozoa after previous enzymatic and cytochemical treatment. After neuraminidase digestion $(\mathbf{a}, \mathbf{b})$ no difference in labelling density was noted for the postacrosomal region whereas a slight decrease was observed over the acrosomal plasmalemma. Treatment of sperm cells with phosphatase selectively interfered with labelling in the postacrosomal region $(\mathbf{c}, \mathbf{d})$. Homogeneous labelling was still present after $\alpha$-mannosidase treatment $(\mathbf{e}, \mathbf{f})$. However, acid hydrolysis $(\mathbf{g}, \mathbf{h})$, methylation $(\mathbf{i}, \mathbf{j})$ and $\beta$-elimination $(\mathbf{k}, \mathbf{l})$ completely prevented labelling with cationised gold. Secondary electron micrographs showing plasmalemma $(\mathbf{a}, \mathbf{c}, \mathbf{e}, \mathbf{g}, \mathbf{i}, \mathbf{k})$ and backscattered electron micrographs revealing gold particles $(\mathbf{b}, \mathbf{d}, \mathbf{f}, \mathbf{h}, \mathbf{j}, \mathbf{l})$. Bar $1 \mu \mathrm{m}$ et al. 1990). The reason for this discrepancy is unclear although we suspect differences in methods used to account for this variation. It would seem, however, that differences in distribution and density of anionic sites are more easily assessed on scanning electron micrographs of whole cells after exposure to cationised colloidal gold than on ultrathin sections after colloidal iron hydroxide labelling.

Phosphate and carboxyl groups are in an ionised state at $\mathrm{pH}$ 2.5. Both phosphatase and neuraminidase selectively affected the labelling pattern. Phosphatase treatment interfered with binding of cationised gold to the postacrosomal region whereas neuraminidase reduced labelling density over the acrosomal and equatorial segments. Thus, phospholipids are likely to account to a substantial degree for the binding of cationised colloidal gold over the postacrosomal region. Neuraminidase has been reported to be effective in removing negative charges from hamster, rat and mouse epididymal spermatozoa (Moore 1979) and from peritoneal mesothelium (Ohtsuka and Murakami 1994). In several other investigations, however, anionic sites supposed to belong to sialic acid residues were insensitive to neuraminidase treatment as concluded from both labelling experiments and electrophoretic mobility (Fléchon and Morstin 1975; Lopez et al. 1987; Moore 1979; Yanagimachi et al. 1972). In our experiments, neuraminidase treatment did not affect labelling of the postacrosomal plasmalemma but somewhat reduced the number of binding sites for cationised gold over the acrosomal area. Neuraminidases have preferences for different linkages of sialic acid, and factors determining resistance to enzymatic hydrolysis have been established (Parillo et al. 1997; Rodriguez et al. 1996). Thus, enzymatic digestion is not effective in every case. We, therefore, subjected boar spermatozoa to biochemical procedures as well. Acid hydrolysis and methylation of sperm cells completely abolished cationised gold labelling. Acid hydrolysis removes sialic acid and methylation esterifies carboxyl and cleaves sulphate groups. Elimination of colloidal iron hydroxide binding after methylation has also been reported for stallion spermatozoa (Lopez et al. 1987). Methylation is not group specific, but proceeding from a lack of sulphate groups as mentioned above, sensitivity to methylation is likely to betray the presence of carboxyl groups. Presence of sialic acid residues at the sperm surface has been demonstrated in several species (Lopez et al. 1987; Retamal et al. 2000; Schröter et al. 1999; Toshimori et al. 1988). Indirect support for this contention also comes from the specific attachment of Sendai virus or influenza virus and from evidence that sperm cells acquire sialic acid groups during epididymal transit (Holt 1980; Olson and Hamilton 1978). Therefore, we attribute binding of cationised gold over the acrosomal region to the presence of neuraminidase-resistant sialic acid residues. The observation that $\beta$-elimination drastically reduced labelling with cationised colloidal gold further suggests that sialic acid residues are associated to a substantial degree with $O$-linked oligosaccharides (Arenas et al. 1998). In addition, $\alpha$-mannosidase treat- 
ment did not prevent labelling with cationised colloidal gold as compared to sham-treated spermatozoa. This finding lends further support to the conclusion that $O$-linked glycans bear most detectable sialic acid residues since one would expect $\alpha$-mannosidase to remove terminal sialic acid residues together with the high mannose core of $N$-linked carbohydrates (Arenas et al. 1998; Kirchhoff and Schröter 2001). Apart from the presence of phosphate groups of phospholipids demonstrated in the postacrosomal region, the bulk of negative charges at the sperm surface, thus, appears to be attributable to carboxyl groups of sialic acid residues. Analogously, sialylated $\mathrm{N}$-acetyllactosamine repeats in $O$-linked carbohydrate chains have also been reported in porcine zona pellucida glycoproteins (Hokke et al. 1994).

Net negative surface charge has long been suspected to be an indicator of sperm maturity (Bedford 1963). This contention is supported by increasing evidence that charge interactions may mediate recognition events and cellular adhesion (Philip et al. 1997). It has been shown that the zona pellucida is virtually devoid of negatively charged constituents and thus might attract spermatozoa whereas the cumulus cells are intensely labelled with polycationic probes and, therefore, will repel sperm cells (Skutelsky et al. 1992). In the bull, capacitation is associated with a reduction of the net negative surface charge of sperm cells and electronegativity is inversely correlated with the penetration of zona-free hamster eggs (Iqbal and Hunter 1995). A main purpose of capacitation then would be to remove surface charges so as to allow particle clustering and formation of protein-free areas of lipid as a prerequisite for membrane fusion events. Taken together, these observations lend considerable support to the contention that charge interactions might play a pivotal role in sperm-egg interactions. The use of cationised colloidal gold and SEM should help unravel the functional implications of anionic sites in sperm maturation and fertilisation.

Acknowledgements We gratefully acknowledge the outstanding support from the SUISAG (Knutwil, Switzerland), who kindly provided weekly boar sperm samples for more than 2 years. We also are indebted to C. Furer, C. Hug, S. König and P. Thomi for technical and secretarial assistance.

\section{References}

Arenas MI, Madrid JF, Bethencourt FR, Fraile B, Paniagua R (1998) Identification of $\mathrm{N}$ - and $\mathrm{O}$-linked oligosaccharides in the human epididymis. J Histochem Cytochem 46:1185-1188

Bedford JM (1963) Changes in the electrophoretic properties of rabbit spermatozoa during passage through the epididymis. Nature 200:1178-1180

Braet F, Dezanger R, Wisse E (1997) Drying cells for SEM, AFM and TEM by hexamethyldisilazane: a study on hepatic endothelial cells. J Microsc 186:84-87

Danon D, Goldstein L, Marikovsky Y, Skutelsky E (1972) Use of cationized ferritin as a label of negative charges on cell surfaces. J Ultrastruct Res 38:500-510

Delgado NM, Reyes R, Carranco A, Huacuja L, Merchant H, Rosado A (1990) Glycosaminoglycan-sulfate as plasma membrane component of pig spermatozoa. Arch Androl 25:121-129
Fléchon J-E (1975) Ultrastructural and cytochemical modifications of rabbit spermatozoa during epididymal transport. In: Hafez ESE, Thibault CG (eds) The biology of spermatozoa. Transport, survival and fertilizing ability. Karger, Basel, pp 36-45

Fléchon J-E, Morstin J (1975) Localization of glycoproteins and of negative and positive charges in the cell coat of ejaculated rabbit and bull spermatozoa (author's translation). Ann Histochim 20:291-300

Friess AE, Liebich H-G (1972) Ultrahistochemische Untersuchungen an der Glykokalyx von Lymphozyten aus dem Ductus thoracicus der Ratte. Z Zellforsch 134:143-152

Gasic GJ, Berwick L, Sorrentino M (1968) Positive and negative colloidal iron as cell surface electron stains. Lab Invest 18: 63-71

Hokke CH, Damm JBL, Penninkhof B, Aitken RJ, Kamerling JP, Vliegenthart JFG (1994) Structure of the $O$-linked carbohydrate chains of porcine zona pellucida glycoproteins. Eur J Biochem 221:491-512

Holt WV (1980) Surface-bound sialic acid on ram and bull spermatozoa: deposition during epididymal transit and stability during washing. Biol Reprod 23:847-857

Iqbal N, Hunter AG (1995) Comparison of various bovine sperm capacitation systems for their ability to alter the net negative surface charge of spermatozoa. J Dairy Sci 78:84-90

Kashio N, Tsuyama S, Ihida K, Murata F (1992) Cationic colloidal gold - a probe for light-microscope and electron-microscopic characterization of acidic glycoconjugates using poly-1-lysine gold complex. Histochem J 24:419-430

Kirchhoff C, Schröter S (2001) New insights into the origin, structure and role of Cd52: a major component of the mammalian sperm glycocalyx. Cells Tissues Organs 168:93-104

Leis O, Madrid JF, Ballesta J, Hernandez F (1997) $N$ - and $O$-linked oligosaccharides in the secretory granules of rat Paneth cells: an ultrastructural cytochemical study. J Histochem Cytochem 45:285-293

Lillie RD (1965) Histopathologic technical and practical histochemistry. McGraw-Hill, New York

Lopez ML, Souza W de, Bustos-Obregon E (1987) Cytochemical analysis of the anionic sites on the membrane of the stallion spermatozoa during the epididymal transit. Gamete Res 18: 319-332

Moore HDM (1979) The net surface charge of mammalian spermatozoa as determined by isoelectric focusing. Changes following sperm maturation, ejaculation, incubation in the female tract, and after enzyme treatment. Int J Androl 2:449-462

Nevo AC, Michaeli I, Schindler H (1961) Electrophoretic properties of bull and of rabbit spermatozoa. Exp Cell Res 23:69-83

Ohtsuka A, Murakami T (1994) Anionic sites on the free surface of the peritoneal mesothelium: light and electron microscopic detection using cationic colloidal iron. Arch Histol Cytol 57: 307-315

Olson GE, Hamilton DW (1978) Characterization of the surface glycoproteins of rat spermatozoa. Biol Reprod 19:26-35

Ono K, Katsuyama T, Hotchi M (1983) Histochemical application of mild alkaline hydrolysis for selective elimination of $O$-glycosidically linked glycoproteins. Stain Technol 158:309-312

Parillo F, Stradaioli G, Supplizi AV, Monaci M (1997) Detection of glycoconjugates in the ductus epididymis of the prepubertal and adult horse by lectin histochemistry. Histol Histopathol 12:691-700

Philip J, Rodriguez LG, Bada RA, Ambroise FG, Hernandez UA, Oppenheimer SB (1997) Charge interactions in sperm-egg recognition. Acta Histochem 99:401-410

Pursel VG, Johnson LA (1976) Frozen boar spermatozoa: methods of thawing pellets. J Anim Sci 42:927-31

Retamal C, Urzua J, Lorca C, Lopez ML, Alves EW (2000) Changes in the plasma membrane proteins of stallion spermatozoa during maturation in the epididymis. J Submicrosc Cytol Pathol 32:229-239

Rodriguez PE, Maggio B, Cumar FA (1996) Acid and enzymatic hydrolysis of the internal sialic acid residue in native and chemically modified ganglioside GM1. J Lipid Res 37:382-390 
Saga K (1998) Application of cationic colloidal gold staining for the demonstration of anionic sites. Acta Histochem Cytochem $31: 1-8$

Schröter S, Osterhoff C, Mcardle W, Ivell R (1999) The glycocalyx of the sperm surface. Hum Reprod Update 5:302-313

Skutelsky E, Roth J (1986) Cationic colloidal gold: a new probe for the detection of anionic cell surface sites by electron microscopy. J Histochem Cytochem 34:693-696

Skutelsky E, Maymon BB, Maymon R, Shalgi R (1992) Histochemical characterization of anionic constituents in oocyte-cumulus complex of rats. Histochemistry 98:299-304

Skutelsky E, Shoichetman T, Hammel I (1995) An histochemical approach to characterization of anionic constituents in mast cell secretory granules. Histochem Cell Biol 104:453-458

Stoffel MH, Frethem C, Hamilton DW (1991) High-resolution scanning electron imaging of rat epididymal sperm after various aldehyde fixation protocols. J Cell Biol 115:50a
Ting-Beall HP, Zhelev DV, Hochmuth RM (1995) Comparison of different drying procedures for scanning electron microscopy using human leukocytes. Microsc Res Tech 32:357-361

Torihara K, Morimitsu T, Suganuma T (1995) Anionic sites on Reissner's membrane, stria vascularis, and spiral prominence. J Histochem Cytochem 43:299-305

Toshimori K, Araki S, Oura C (1988) Masking of sperm maturation antigen by sialic acid in the epididymis of the mouse. An immunohistochemical study. Histochemistry 90:195-200

Ueda H, Kato Y, Ohno S (1998) Quantitative detection of anionic sites in rat femoral cartilage using cationic colloidal gold at low pH levels. Histol Histopathol 13:1001-1009

Wall J, Ayoub F, Oshea P (1995) Interactions of macromolecules with the mammalian cell surface. J Cell Sci 108:2673-2682

Yanagimachi R, Noda YD, Fujimoto M, Nicolson GL (1972) The distribution of negative surface charges on mammalian spermatozoa. Am J Anat 135:497-520 